the veins on the forehead of a little patient so enlarged, as in the case in question.

In conclusion, I may repeat that no case could present a more marked diathesis of the convulsive character than this little patient. One of nine children, all of whom had suffered from the crowing convulsion, three having died, and one having presented the appearance of enlarged thymus, the principle of the total removal of all irritation, gastric, intestinal, and dental, succeeded, nevertheless, in subduing the disease. The stomach and bowels having been cleared, we procured a healthy nurse, letting her milk be the only food; we kept the bowels free by the mildest measures (for $\mathbf{I}$ am convinced that rough ones, and especially calomel and senna, frequently induce the attack); and we kept the gums free from irritation by the use of the gum-lancet; and under this treatment the child has done well. A cold spirit-lotion applied to the crown of the head, and change of air, and especially the sea-breezes, doubtless also contributed their aid in the cure. I have frequently had to remark the baneful influence of the north-east wind, and the beneficial influence of change of air on this disease, as in pertussis, with which it seems, indeed, to possess various points of resemblance, not to say connection.

During the course of the treatment I had the pleasure of receiving several interesting reports from $M r$. Mimpriss, one or two of which I append:-

Wandsworth-road, April 2s, 1842.

Dear Sir,-I am sure you will be much gratified to hear that your plan of treating the disorder of Mr. Grey's infant has been signally successful.

We have adhered rigidly to the rule prescribed since you saw him, and in the period I believe only four or five very slight spasms have been noticed. He takes his nourishment from the nurse with avidity, and appears to digest it; his cough is relieved, and his appearance is altogether improved. His bowels keep in a moderately lax state, without signs of irritation; I can detect no febrile excitement. The turgescence of the veins of the forehead, I think, continues. I continued the lancing of the gums twice a-day until yesterday, when $I$ only did it once, and the same to-day, as the gums, where divided, continue soft and open, and slightly ulcerated, as well as from the amelioration of the symptoms for which the lancing was ordered. I am anxious to have your advice by the bearer, how I shall go on in this matter, and if we shall still administer the calomel and rhubarb every night. I am, dear Sir, most respectfully yours,

T. R. Mimpriss.

Wandsworth-road, May 4, 1842.

Dear Sir,-Mrs. Grey's infant has continued to improve since my last report. I believe no spasm has been noticed; the different functions of the body go on in a healthy way. The treatment you suggested has been unremittingly carried out, excepting that since I last wrote the gums have been only lanced once a-day, \&rc. \&c.

\section{NOTE ON NEURITIC SCIATICA.} By Dr. Marshall Hall.

THE symptoms of true neuritic sciatica have not, I think, been fully described. They consist, at the first, of augmented sensibility, and of augmented muscular contraction; in other words, of pain in the nerve, and of spasm and quivering of the muscles to which the nerve is distributed. Afterwards there is numbness, or a sense of "pins and needles" in one (the outer) side of the foot, and muscular debility.

These symptoms are perfectly distinct and pathognomonic. During recovery they subside, and leave a distinct tenderness along the course of the nerve, and a disposition to augmentcd action, or cramp in the muscles. On one occasion when the pain and numb. ness, and muscular quivering and weakness had greatly subsided, there was such excruciating pain and spasm in the gastrocnemii, on attempting to pull off the boot, without the aid of the boot-jack, that the patient had almost fainted away.

Mercurial and other purgative medicines, but especially a hot bath ęvery night on going to bed at $103^{\circ}$, for fifteen minutes, were the most effectual remedies. Fomentations did good.

There was a disposition to an early morning exacerbation. The jar of a carriage was intolerable.

This neuritic sciatica is of an essentially different character from any muscular rheumatism, lumbago. As the latter is inflam. mation of the muscular fibre, the former is most distinctly, in its two-fold set of symptoms, a neuritis. The numbness is similar to that experienced in the second stage of odontalgia, doubtless from hyperæmia of the neurilemma and compression of the nervous substance.

London, June 23, 1842.

\section{PUERPERAL FEVER}

DEVELOPED UNDER THE INFLUENCE OF TYPHUS CONTAGION.

\section{To the Editor of The Lancet.}

Sir,-I forward to you the present communication, with the view of recording what appears to me to be a highly interesting case in the practice of obstetric medicine. The diversity of opinion that exists, and the importance of the subject, render the reporting of individual cases more valuable than crude 